\title{
Perception of Suicidal Attempts among College Students in Malaysia
}

\author{
Cai-Lian Tam \\ Jeffery Cheah School of Medicine and Health Sciences \\ Monash University Sunway Campus, Malaysia \\ E-mail: tam.cai.lian@med.monash.edu.my
}

Teck-Heang Lee (Corresponding author)

School of Business, Monash University Sunway Campus, Malaysia

E-mail: lee.teck.heang@buseco.monash.edu.my

Wai-Mun Har

Faculty of Accountancy \& Management

Universiti Tunku Abdul Rahman (UTAR), Malaysia

E-mail: harwn@mail.utar.edu.my

Li-Chuin Chan

Department of Psychology, School of Health and Natural Sciences

Sunway University College, Malaysia

Received: January 12, 2011 Accepted: March 23, $2011 \quad$ doi:10.5539/ass.v7n7p30

\begin{abstract}
Teenage suicide has become a very serious problem and has been labeled as a growing epidemic by many health professionals worldwide. Through a questionnaire survey, the study aims to examine gender difference in public perceptions on various reasons for and methods used in suicidal attempts among teenagers. 90 college students participated in this study. The results showed a significant difference among males and females for the reasons why teenagers attempt suicide. The reasons were secularism, poor parent-child relationship and atheism. For the methods of suicidal attempts, a significant gender difference was also obtained for the slit wrist method.
\end{abstract}

Keywords: Suicidal attempts, Teenagers

\section{Introduction}

Teenage suicide, unfortunately, occurs in every corner of the world. It is a very serious problem and has been labeled as a growing epidemic by many health professionals worldwide. In Malaysia, the rate of suicide is alarming. According to the report of a local newspaper in Malaysia, Nanyang Siang Pao (2010), there was 445 suicidal cases (347 males and 98 females) reported for the first eight months of 2010 as compared to 290 cases in 2008. This accounts for the generally higher record of suicide attempts in males than females in the Malaysian context. In addition, the rates for those of 30-39 years (109 cases) and 20-29 years old (108 cases) was significantly higher compared with other age cohorts. The report further revealed that suicidal acts are culture-bound. Most cases have been linked to suffering from perceived burdensomeness which includes emotion, study and work (Nanyang Siang Pao, 2010).

Suicide occurs throughout the world in different ways. Various studies have been conducted specifically to examine the relationship of suicidal behavior and the rates of suicidal attempts with the demographics factors such as the sex/gender, race/ethnicity, age, and marital status. Generally, in the U.S, males as a group successfully commit suicide more than three times compared to the females (Williamson \& Shneidman, 1995). It is also found that suicide is more rampant and common among youngsters. Such a finding may due to the different life situations and motives in life among the youngsters, adults and the elderly (Portes, Sandhu \& 
Longwell, 2002). As statistical evidence prove that suicidal behaviors is more rampant among youngsters, this extensive occurrence among youngsters is indeed explained by Erik Eriksson who indicated the importance of social surrounding in an individuals' overall mental development. Suicide is said to occur due to the failure to master the Eriksson's eight developmental stages (Portes, Sandhu \& Longwell, 2002).

Eriksson asserts that during adolescence, the adolescents undergo the process of resolving the issue of identity versus confusion. During this period of time, they undergo the search for their own identity through sexual, social, ideology and career domain (Portes, Sandhu \& Longwell, 2002). Therefore, by the means of Eriksson's theory on development the undercurrent reason for the occurrence of suicide among the youngsters can be explained. Depressions among youngsters due to their inability to find their identity results in the emergence of suicidal behavior and causes them to react destructively to situations without being able to understand the situation.

Besides, various studies as highlighted in section 2.1 of the paper indicated that gender differences have made a distinction between suicide attempts and completion, with consideration of actual motives behind such acts. Hence, the findings of this study in turn contribute towards understanding the mental setting of individuals who have attempted suicide, in comparison with intact people and their level of motivation. This implies that suicide intervention should be customised according to adolescents' gender, needs, personality, social environment and other relevant factors (Shain, 2007). Besides, through the present study, it would also raise the awareness of the society that more research is required since information on suicide ideation and non-fatal attempts are only obtainable via self-reports which are subject to numerous influencing factors such as cognitive decline and repression thus lowering its reliability over time (Cantor \& Neulinger, 2000). The present study also aim to gain further understanding of the reasons behind suicidal attempts as well as the opinions of individuals in regards of suicidal methods and interventions.

\section{Literature Review}

For the purposes of this study, suicide will be defined as an intentioned death. It also refers to a self-inflicted death in which one makes an intentional, direct, and conscious effort to end the life of a person (Comer, 2004). A suicide attempt is defined as "any self-injurious behavior with a nonfatal outcome irrespective of intention" (De Wilde, 2000 cited in Pelkonen \& Marttunen, 2003).

This brings up a few interesting questions. Do male and female teenagers who attempt suicide do so for different reasons? What about the ways in which they attempt to kill themselves? Are they similar or very different?

\subsection{Reasons of suicidal attempts and gender differences}

There are many factors contributing to the frequency of suicidal attempts such as hopelessness, personal history of depression and aggressive behaviour, use of alcohol and drugs, family-, school- and peer-related problems, unemployment, and a family history of suicidal behaviour (Wagner, Cole, \& Schwartzman, 1995; Al Ansari et al., 2001). An individual's socioeconomic status can also influence suicidal attempts. Individuals with low income tend to commit suicide more often than better paid individuals (Boxer, Burnett, \& Swanson, 1995). In developing countries, low socioeconomic status is believed to be the main cause of suicide. Another reason why younger people are attempting suicide is because of a loss of a sense of hope and a loss of a sense of the future (Brown, 2001). As times are rapidly changing, teenagers experience a lot of confusion and uncertainty about their future.

Research also indicates that suicidal rates are lower in countries that have a negative point of view about suicide and higher in countries that are less negative in their view of suicide (Kelleher et al., 1998; Lester, 1996, 1998; Neeleman, 1998; Neeleman et al., 1997). Suicidal thoughts and behaviours among friends and family are also important factors that can influence teenagers to attempt suicide. Marušič, Roškar, and Hughes (2004) studied Slovenian adolescents and found that $13 \%$ of the teenagers had a family member who had attempted suicide, $9 \%$ lost a family member as a result of suicide, and half of the females and one third of the males had suicidal thoughts before actually attempting suicide. As teenagers are easily influenced, they might decide to model the behaviour of the people closest to them or those whom they admire.

In Taiwan (Cheng, 1995; Cheng et al., 2000), China (Phillips et al., 2002), and India (Vijayakumar \& Rajkumar, 1999), several research demonstrated a relationship between mental illness and suicidal attempts. According to Stolberg et al. (2002 as cited in Comer, 2004), the majority of all suicide attempters displayed a psychological disorder. Brown (2001) found that suicide rate amongst substance abusers are 12 times that of the general population. In addition, it is also suggested that people who are diagnosed with depression are 22-36 times more 
likely to kill themselves. This rate is disturbing as more and more young people are diagnosed with depression and other mental disorders.

It is likely for one to assume that women are more emotional compared to men and therefore, the rates of suicidal attempts would be higher among females. Indeed, it has been found that women do attempt suicide three times more than men. Nevertheless, men succeed at killing themselves three times more than women (Maris, 2001 as cited in Comer, 2004). It is interesting to note that in China, women's suicide rates are $25 \%$ higher than men (Phillips, Li, \& Zhang, 2002) and in India this rate is equal among males and females (Mayer \& Ziaian, 2002). On the other hand, in India (Mayer \& Ziaian, 2002; Rao, 1991), Pakistan (Saeed et al., 2002), China (Phillips, Li, \& Zhang, 2002), Brazil (Souza, Minayo, \& Malaquias, 2002), and Nigeria (Nwosu \& Odesanmi, 2001) young men are found to be at a higher risk of suicidal attempts.

There are a few studies which have demonstrated differences in the reasons for and methods used to attempt suicide. For example, Hjelmeland and Grøholt (2005) conducted a study on attempted suicides with 98 subjects, 86 of them females and 12 of them males. The subjects were all patients at various hospitals in Norway. Relevant information regarding the attempted suicide was obtained via interviews and questionnaires. 69 of the subjects stated that feelings of loneliness was what had driven them to attempt suicide while the other precipitating factors were mental illness, problems with partner, and rejection by lovers.

Groohi et al. (2006) conducted a study on suicidal behaviour by burns amongst adolescents in Kurdistan, Iran. They had 40 subjects, 34 of them females and 6 of them males, who were admitted into the hospital because of burn injuries. Relevant information was obtained from the adolescent or significant others (e.g. parent, relatives, friends who know the adolescent well). For the majority of the subjects (18), they attempted suicide because of a quarrel with a family member (e.g. parents, brothers, sisters or mother-in-law). The second most frequent reason that caused them to attempt suicide was due to marital conflict. The remaining reasons were conflict with spouse's relatives and having a psychiatric disorder.

\subsection{Methods a of suicidal attempts and gender differences}

One of the reasons for the difference in suicide rates between genders could be due to the fact that men and women choose different methods (Ayd \& Palma, 1999 as cited in Comer, 2004). This could be due to the accessibility of certain means. For example, young women in villages in China use strong, concentrated pesticide which can be found in their refrigerators while young men in industrialized nations use guns (Brown, 2001).

In a study conducted on 374 Slovenian juveniles (39 boys, 335 girls) who attempted suicide, Krajnc et al. (1998) found that almost all the subjects had attempted suicide by taking an overdose of drugs $(98.4 \%)$. The remainder attempted suicide by taking an overdose of alcohol. The most common reason offered by the suicide attempters were despair due to disturbed relationships within the family (38\%). Another $21 \%$ attributed the attempts to disappointments, usually in love. Poor school performance accounted for $18 \%$ of the suicide attempts (Krajnc et.al., 1998).

According to Beautrias (2003), the lethality theory posits that males with their tendency to be more aggressive and conformation to the 'traditional masculine' stereotype, prefer to perform suicidal acts with methods of high and immediate lethality in comparison to females. This has been suggested to contribute to elevated male suicide rates. Moscicky (1994) rejected this theory, stating that there is no consideration of an intention to die and self-injury as a potential indicator for help. In agreement, Canetto and Sakinofsky (1998) believe that suicide intent is distinct from the chosen method and is unreflective of the outcome. Individuals may not survive from acts thought to be non-fatal (i.e. drug overdose) while others may survive a seemingly fatal act (i.e. car crash). It was concluded that despite the influence of method lethality on gender differences in mortality, most female suicide attempts have non-fatal motivations unlike male counterparts. Nevertheless, Beautrais (2003) found that suicide method choice can explain gender disparities in outcome of more serious suicide-attempting youths.

\subsection{Ways of preventing suicidal attempts}

Based on the above evidences discussed in section 2.2 and 2.3, it is clear that there are various factors that may instigate a suicide attempt. Moreover, there seems to be cultural influences as well, with different countries having different factors as the main cause.

Instead of just focusing on the negative issues, let's look at the brighter side and figure out what can be done to prevent suicide attempts. Some studies have offered some intriguing answers. A study was conducted on 2722 adolescents by Flouri and Buchanan (2002) and they found that parental involvement (e.g. direct interaction with the child, availability to the child, and responsibility for the care of the child) is a protective factor as it seems to prevent suicide attempts. Religion also seems to play a part in preventing suicides. It has been noted that Islamic 
countries tend to have one of the lowest suicide rates in the world (Brown, 2001). This could be due to the fact that Islam fervently condemns suicide.

\subsection{Objectives and hypotheses of study}

The current study focuses on the college student's point of view about teenage suicide: its reasons, methods and possible ways of preventing it. In this study, the definition of teenagers is defined as any individual between the ages of 13 to 20 years. The aims of the study are to find out whether there is gender differences exist in the participants' perceptions of the reasons for suicidal attempts in males and females, and the methods used by both genders to attempt suicide. Due to interest, we also intend to find out what were the participants' perceptions of the best ways to prevent suicide attempts amongst teenagers. The hypotheses of the study are:

H1: There would be gender differences in the reasons for suicidal attempts amongst males and females.

$\mathrm{H} 2$ : There would be gender differences in the methods used in suicidal attempts amongst males and females.

\section{Method}

\subsection{Respondents}

The respondents of this study were 90 college students, 45 males and 45 females. Their age ranged from $18-20$ years and the mean age of the participants was 19.46 years. There were 11 Malays, 52 Chinese, 6 Indians, and 21 who were of other races. 89 respondents were single and only one was married. There were 30 Buddhist 12 Islam, $31 \mathrm{Hindu}, 9$ Christian and 8 of others. Forty five respondents had their highest education level at SPM or equivalent, 6 at STPM, A-Levels, or equivalent, 13 at diploma, and 26 at undergraduate program. All respondents agreed to take part in the survey voluntarily.

\subsection{Measurements}

The questionnaire used was a self-constructed questionnaire. The questionnaire consisted of 3 parts that measured public's perception on reasons for suicide attempts, methods of suicide Attempts and ways to prevent suicidal attempts. The questionnaire of this study is available in the appendix.

\subsubsection{Public's Perception: Reasons for Suicide Attempts}

There are 13 items for the inventory. Participants are required to rank the reasons for teenage suicide attempts from 1-most frequent to 13-least frequent. Participants had to rank the reasons for both male and female based on their own opinions.

\subsubsection{Public's Perception: Methods of Suicide Attempts}

There are 9 items for the inventory. Participants are required to rank the methods teenagers use for suicide attempts from 1-most frequent to 9-least frequent. Participants had to rank the methods for male and female based on their own opinions.

\subsubsection{Public's Perception: Ways to Prevent Suicidal Attempts}

There are 6 items for the inventory. Participants are required to rank the best way to prevent teenage suicide attempts from 1- most important to 6-least important. Participants had to rank the best way for prevention according to their own opinions.

\subsection{Procedure}

The survey was conducted in a private college in January 2008. Participants were required to fill in a consent letter to show that they agreed to take part in the study. Participants were allocated an average of 30 minutes to answer the questionnaire and all were returned upon completion.

\section{Results}

Reasons of Suicide Attempt between males and females were analyzed to find out if there was a gender difference regarding the way subjects viewed factors that influence male and female suicides. Research revealed that, $\mathrm{t}(88)=-2.887, \underline{\mathrm{p}}<.01$. Therefore, there is a significant difference between how male and female subjects view secularism as a reason for committing suicide amongst male teenagers. The mean for secularism (male attempters) for males is 8.22 while the mean for the same factor for females is 9.82. See Table 1.

The results revealed that, $\mathrm{t}(88)=-2.328, \mathrm{p}<.05$. Therefore, there is a significant difference between how male and female subjects view poor parent-child relationship as a potent reason for influencing suicide attempts 
amongst females. The mean for poor parent-child relationship (female attempters) for males is 4.84 whereas the mean for the same factor for females is 6.27. See Table 1.

As for atheism, research results revealed that, $\mathrm{t}(88)=-2.100, \mathrm{p}<.05$. Thus, there is a significant difference between how male and female subjects view atheism as a reason for influencing suicide attempts amongst females. The mean for atheism (female attempters) for males is 8.62 whilst the same factor for females is 9.84 . See Table 1.

Research results revealed that, $\mathrm{t}(88)=-2.488, \mathrm{p}<.05$. Thus, there is a significant difference between how male and female subjects perceive the influence of secularism in suicide attempts amongst females. The mean for secularism (female attempters) for males is 8.69 whereas the same factor for females is 10.02. The rest of the results were insignificant.

\section{Insert Table 1}

Methods of Suicide Attempts between males and females was analyzed to find out if there was a gender difference in the way subjects viewed which method is being used most often for suicide attempts. Research revealed that, $\mathrm{t}(88)=2.054, \underline{\mathrm{p}}<.05$. There is a significant difference between how male and female subjects perceive 'slit wrist' method as a common method in committing suicide among males. The mean for 'slit wrist' method (male attempters) for males is 5.36 while the mean for the same method for females is 4.44 . The rest of the analysis yields no significant results. See Table 2.

\section{Insert Table 2}

Best Method for Preventing Teenage Suicidal Attempts was analyzed to find out which factors represent the best way to prevent teenage suicide. A mean score for the method was computed. The result is as follows: healthy relationship with parents (1.93), education (2.41), religion (2.83), social workers (4.10) and psychologist (3.86), and others which include coping mechanism, stress reduction and social support (4.87). The numbers in parenthesis are the mean scores which represent the best way to prevent teenage suicide. See Table 3.

\section{Insert Table 3}

\section{Discussion and Conclusion}

The research hypothesis was proved right as our results showed that there is a gender difference in terms of how female and male participants view the reasons for and methods used in attempting suicide.

Female subjects viewed secularism as a less frequent reason used by male suicide attempters than male subjects do. This may be due to the fact that female subjects view more pressing factors other than secularism as reasons why male teenagers attempt suicide. Besides that, the sample was collected from an urban area where most adolescents lead busy lives. Therefore, it is not surprising that males do not have much time to devote to religion.

Male subjects viewed atheism as a more frequent excuse for females committing suicide than do male subjects. It is the same for secularism as male subjects seem to think that females who commit suicide use this reason more than do male subjects. This may mean that males think that religion play an important role in a female's life as an absence in the belief of God or God's existence tend to lead to more suicidal attempts amongst females.

Female subjects viewed poor parent-child relationship as a less important or less often reason as to why females commit suicide. The females in today's modern world consider themselves as more independent and are able to make their own decisions in life. They are not that family-oriented and also do not seek much family approval in life issues as they want to believe that only they themselves have control over their life.

Female subjects seem to perceive that male suicide attempters would slit their wrist more than female subjects do. This result is somewhat surprising as for a long time, females have always been known to be more emotional and the easiest way to attempt suicide is by slitting the wrist. However, it now appears that there is a shift in the female public's mindset. This could be due to this method being more painful and it is considered macho for the males to be able to bear pain before they take their life. Besides, it could be because females believe that males will attempt suicide using the most effective way when done properly, which is along the blood vein and not across it.

As adolescents go through their teenage years, there is a need to search for their identity and develop individuality. Many of them begin to view the relationship with their parents differently and also express themselves in a markedly dissimilar way from what their parents are used to. This can cause parents to misinterpret their children's action and label them as rebellious and hard to deal with. All these changes can add up to a very stressful life. According to Taylor and Stansfeld (1984 as cited in Comer, 2004), adolescents react to events in their life more sensitively and hastily. Therefore, in times of stress they do not know how to act wisely 
and are more likely to view suicide as the only solution to their problems. However, most of these teenagers do not attempt suicide to harm themselves. They simply want to make people around them understand how desperate they are, get help, or teach others around them a lesson (Leenaars et al., 2001; Boergers et al., 1998 as cited in Comer, 2004).

Participants in this study believed that a healthy relationship with parents is the best way to prevent teenage suicides from occurring. Participants ranked education, social workers, religion and psychologists as other useful prevention methods in order of importance.

The strengths of this study are that equal group sizes of males and females were used allowing a more accurate group comparison. Besides that, the results obtained are based on the perception of the adolescents themselves about what they think would most likely motivate their peers to attempt suicide and also what would most likely prevent their peers from attempting suicide.

There are also several limitations in this study. First, the questionnaire used in the survey was self-developed and the validity of the study cannot be determined. Secondly, the participants recruited in this study were only from a private college in Malaysia and there is very low external validity.

There are several things which could be improved such as conducting a similar research in the future. The selection of 90 students from one single college is considered as limitation of the study. A bigger sample size consists of several public and private universities should be adopted in future as to improve the generalization of the sample. Future researchers could also use more thorough and valid questionnaires in their survey. Besides that, obtaining participants from all walks of life would also help improve external validity. An area where more research could be done is effective methods of preventing suicide attempts among teenagers.

The Malaysian National Representative of the International Association for Suicide Prevention reported that Malaysia's suicide rate was at the mid-level, and quite near to the rate of the United States. Many of the Malaysian families were reluctant to report suicide incidents due to the forbidden of their religion. It is crucial to know that to attempt suicide is considered as a crime under the Malaysian law (The Star, 2011). Result of present study has generated some new contribution to the existed literature. For example, most suicide cases in Malaysia would be considered as the anomic suicide due to the deterioration for the integration of society. Many of the individuals in the Malaysian society would feel left out, lonely and less anchored due to the drastic change of the society. Coping mechanism plays a very important role to manage stress effectively. It is believed that constructive coping strategies would also help to reduce suicidal rate due to the quick society changes.

Through the findings of the present study, it has implied that the feelings of helplessness, ambivalence and hopelessness may overwhelm male adolescents due to poor outlet and coping strategies. Furthermore, significant gender differences are present in quality of life ratings. Females, especially younger groups, recorded significantly lower ratings in life quality with higher distress levels from psychiatric disorders relative to their male counterparts (Zhang et al., 2005). It was implied that women more readily express their experience of well-being in a holistic manner while men regard physical well-being separately from psychosocial elements. This study however was limited in sample size and instruments of measure (Gamma \& Angst, 2001).

According to Bongar (1991), a risk management perspective help to provide personal and professional competencies in treating the at risk patients. It is essential for the clinicians to take special precautions when assessing and treating patients with chronic suicidal attempts. In addition, family involvement for support would definitely improve the compliance.

In conclusion, the present result shows that there are many factors that influence whether a teenager will attempt suicide or not. The study also reveals that it is not advisable to lay the blame of teenage suicidal attempts or teenage suicides onto one single factor as there are many factors that are inseparable and inter-related. For example, financial problems cause stress. Stress brings about depression and depressed individuals are more prone to attempt suicide. Depending on the factors that researchers focus on, they may find different reasons for the same phenomena. Therefore, the need for a meta-analysis or more thorough research is apparent.

\section{References}

Al Ansari, Ahmed, M., Hamadeh, R. R., Matar, A. M., Marhood, H., Buzaboon, B. Y., \& Raees, A. G. (2001). Risk factors associated with overdose among Bahraini youth. Suicide and Life-Threatening Behavior, 31, 197-206.

Beautrais, A. L. (2003). Suicide and serious suicide attempts in youth: A multiple-group comparison study. American Journal of Psychiatry, 160 (6), 1093-1099. 
Bonger, B. (1991). The suicidal patient: Clinical and legal standards of care. Washington, DC: American Psychological Association.

Boxer, P. A., Burnett, C., \& Swanson, N. (1995). Suicide and occupation: A review of the literature. Journal of Occupational and Environmental Medicine, 37, 442-452.

Brown, P. (2001). Choosing to die - a growing epidemic among the young. Bulletin of the World Health Organization, 79, 1175-1177.

Canetto, S. S. \& Sakinofsky, I. (1998). The gender paradox in suicide. Suicide and Life-Threatening Behaviour, 28(1), 1-23.

Cantor, C. \& Neulinger, K. (2000). The epidemiology of suicide and attempted suicide among young Australians. New Zealand Journal of Psychiatry, 34, 370-387.

Cheng, A. T. A. (1995). Mental illness and suicide: A case-control study in East Taiwan. Archives of General Psychiatry, 52, 594-603.

Cheng, A. T. A., Chen, T. H. H., Chen, C. C., \& Jenkins, R. (2000). Psychosocial and psychiatric risk factors for suicide: Case-control psychological autopsy study. British Journal of Psychiatry, 177, 360-365.

Comer, R. J. (2004). Abnormal psychology: Fifth edition. New York: Worth Publishers.

Flouri, E., \& Buchanan, A. (2002). The protective role of parental involvement in adolescent suicide. Crisis, 23, $17-22$.

Gamma, A. \& Angst, J. (2001). Concurrent psychiatric comorbidity and multimorbidity in a community study: Gender differences and quality of life. European Archive of Psychiatry and Clinical Neuroscience, 251 (Suppl. 2), 11/43-11/46.

Groohi, B., Rossignol, A. M., Barrero, S. P., \& Alaghehbandan, R. (2006). Suicidal behavior by burns among adolescents in Kurdistan, Iran: A social tragedy. Crisis, 27, 16-21.

Hjelmeland, H., \& Grøholt, B. (2005). A comparative study of young and adult deliberate self-harm patients. Crisis, 26, 64-72.

Kelleher, M. J., Chambers, D., Corcoran, P., Williamson, E., \& Keeley, H. S. (1998). Religious sanctions and rates of suicide worldwide. Crisis, 19, 78-86.

Krajnc, M. S., Schmidt, I., Gregoric, A., \& Dogsa, I. (1998). Suicide attempts in Slovenian juveniles, 1978-1994. Nord J Psychiatry, 52, 487-492.

Lester, D. (1996). Suicide in Indian states and religion. Psychological Reports, 79, 342.

Lester, D. (1998). Ethnicity, religion and suicide in Swiss cantons. Perceptual and Motor Skills, 86, 1210.

Marušič, A., Roškar, S., \& Hughes, R. H. (2004). Familial study of suicidal behavior among adolescents in Slovenia. Crisis, the Journal of Crisis Intervention and Suicide Prevention, 25, 74-77.

Mayer, P., \& Ziaian, T. (2002). Suicide, gender, and age variations in India: Are women in Indian society protected from suicide? Crisis, 23, 98-103.

Moscicki, E. K. (1994). Gender differences in completed and attempted suicides. Analysis of Epidemiology, 4, 152-158.

Nanyang Siang Pao. (2010). 21 December, A19.

Neeleman, J. (1998). Regional suicide rates in the Netherlands: Does religion still play a role? International Journal of Epidemiology, 27, 466-472.

Neeleman, J., Halpern, D., Leon, D., \& Lewis, G. (1997). Tolerance of suicide, religion and suicide rates: An ecological and individual study in 19 Western countries. Psychological Medicine, 27, 1165-1171.

Nwosu, S. O., \& Odesanmi, W. O. (2001). Pattern of suicides in Ile-Ife, Nigeria. West African Journal of Medicine, 20, 259-262.

Pelkonen, M., \& Marttunen, M. (2003). Child and adolescent suicide: Epidemiology, risk factors, and approaches to prevention. Pediatr Drugs, 5(4), 243-265.

Phillips, M. R., Li, X., \& Zhang, Y. (2002). Suicide rates in China, 1995-99. Lancet, 359, 835-840.

Phillips, M. R., Yang, G., Zhang, Y., Wang, L., Ji, H., \& Zhou, M. (2002). Risk factors for suicide in China: A national case-control psychological autopsy study. Lancet, 360, 1728-1736. 
Portes, P. R., Sandhu, D. S., \& Longwell, R. (2002). Understanding adolescence suicide: A psychological interpretation of developmental and contextual factors. Adolescence, 37, 148-158.

Rao, A. V. (1991). Suicide in the elderly: A report from India. Crisis, 12, 33-39.

Saeed, A., Bashir, M. Z., Khan, D., Iqbal, J., Raja, K. S., \& Rhehman, A. (2002). Epidemiology of suicide in Faisalabad. Journal of Ayub Medical College, 14, 34-37.

Shain, B. N. (2007). Suicide and suicide attempts in adolescents. Pediatrics, 120, 669-676.

Souza, E. R., Minayo, M. C., \& Malaquias, J. V. (2002). Suicide by young people in selected Brazilian state capitals. Cadernos de Saude Publica, 18, 673-683.

The Star. (2011). 10 February, Pg 1-6.

Vijayakumar, L., \& Rajkumar, S. (1999). Are risk factors for suicide universal? A case-control study in India. Acta Psychiatrica Scandinavica, 99, 407-411.

Wagner, B. M., Cole, R. E., \& Schwartzman. (1995). Psychosocial correlates of suicide attempts among junior and senior high school youth. Suicide and Life Threatening Behavior, 25, 358-372.

Williamson, J. B., \& Shneidman, E. D. (1995). Death Current Perspectives. California: Mayfield Publishing Company.

Zhang, J., Mckeown, R. E., Hussey, J. R., Thompson, S. J. \& Woods, J. R. (2005). Gender differenced in risk factors for attempted suicide among young adults: Findings from the third national health and nutrition examination survey. Annals of Epidemiology, 15 (2), 167-174. 
Table 1. T-test Analysis for Reasons of Suicide Attempt between Males and Females

\begin{tabular}{llll}
\hline & \multicolumn{3}{c}{ Mean Score } \\
\cline { 2 - 4 } Mariable & Male & Female & $\mathrm{t}(\mathrm{df})$ \\
FP & & & \\
DHL & 4.49 & 4.58 & $-.117(88)$ \\
PPCRS & 4.53 & 3.36 & $1.894(88)$ \\
RRSP & 6.38 & 6.11 & $.405(88)$ \\
PR & 4.67 & 5.38 & $-1.135(88)$ \\
STS & 6.13 & 5.40 & $1.225(88)$ \\
HMD & 4.20 & 4.56 & $-.618(88)$ \\
ATH & 6.98 & 7.44 & $-.661(88)$ \\
EXP & 8.51 & 9.22 & $-1.059(88)$ \\
SCM & 8.87 & 8.78 & $.169(88)$ \\
LSE & 8.22 & 9.82 & $-2.887(88)^{* *}$ \\
PPSA & 6.91 & 5.76 & $1.699(88)$ \\
OTH & 8.73 & 8.71 & $.037(88)$ \\
Female & 9.76 & 9.51 & $.227(88)$ \\
FP & & & \\
DHL & 6.78 & 7.80 & $-1.505(88)$ \\
PPCRS & 3.89 & 3.40 & $.843(88)$ \\
RRSP & 4.84 & 6.27 & $-2.328(88)^{*}$ \\
PR & 3.67 & 3.98 & $-.435(88)$ \\
STS & 6.53 & 6.18 & $.574(88)$ \\
HMD & 5.56 & 5.04 & $.842(88)$ \\
ATH & 7.87 & 7.02 & $1.344(88)$ \\
EXP & 8.62 & 9.84 & $-2.100(88)^{*}$ \\
SCM & 8.71 & 7.98 & $1.240(88)$ \\
LSE & 8.69 & 10.02 & $-2.488(88)^{*}$ \\
PPSA & 6.69 & 6.58 & $1.681(88)$ \\
OTH & 5.67 & 5.27 & $.527(88)$ \\
& 10.31 & 9.76 & $.526(88)$ \\
\hline
\end{tabular}

$\underline{\text { Key }}$

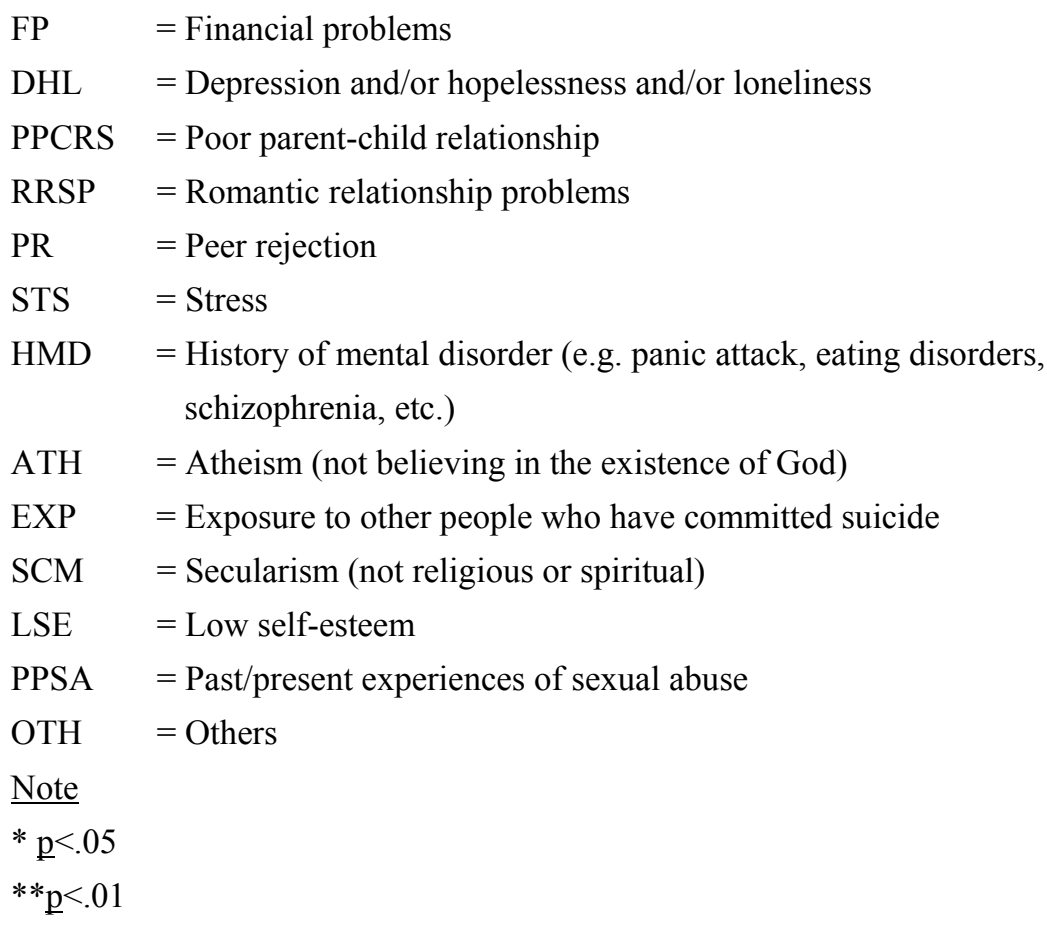


Table 2. T-test Analysis for Methods of Suicide Attempts between Males and Females

\begin{tabular}{llll}
\hline & \multicolumn{3}{c}{ Mean Score } \\
\cline { 2 - 3 } Male & Male & Female & $\mathrm{t}(\mathrm{df})$ \\
OD & & & $.991(88)$ \\
SP & 2.89 & 2.51 & $-.502(88)$ \\
SW & 3.58 & 3.78 & $2.054(88)^{*}$ \\
JH & 5.36 & 4.44 & $.359(88)$ \\
HNG & 3.02 & 2.89 & $-1.120(88)$ \\
JV & 3.60 & 4.07 & $-1.201(88)$ \\
BT & 5.07 & 5.56 & $.438(88)$ \\
DRW & 7.13 & 6.18 & $.521(88)$ \\
OTH & 6.47 & 6.29 & $-.926(88)$ \\
Female & 6.40 & 7.09 & \\
OD & & & $-.447(88)$ \\
SP & 3.62 & 3.82 & $.510(88)$ \\
SW & 2.20 & 2.02 & $1.126(88)$ \\
JH & 3.36 & 2.87 & $1.119(88)$ \\
HNG & 3.93 & 3.58 & $-.776(88)$ \\
JV & 4.58 & 4.87 & $-.409(88)$ \\
BT & 5.96 & 6.11 & $-1.772(88)$ \\
DRW & 6.69 & 7.29 & $.745(88)$ \\
OTH & 6.29 & 6.04 & $-.124(88)$ \\
\hline
\end{tabular}

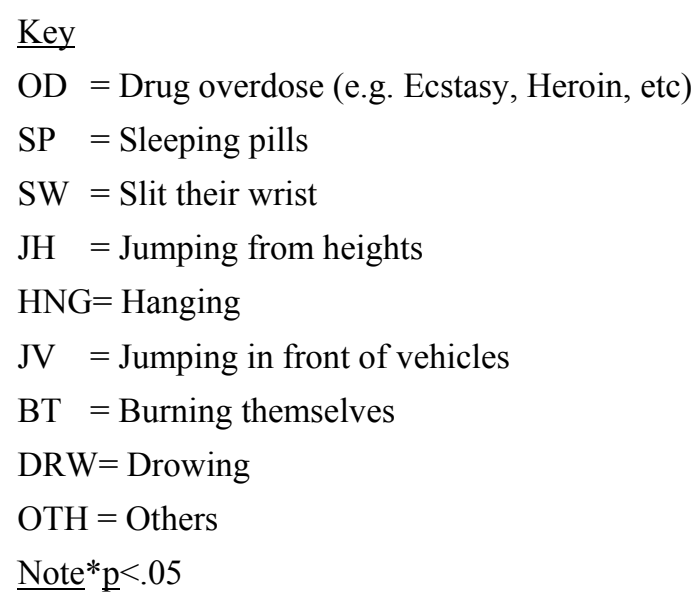

Table 3. Mean Score Table for Best Method for Preventing Teenage Suicidal Attempts

\begin{tabular}{ll}
\hline Factor & Mean Score \\
Healthy relationship with parents & 1.93 \\
Education & 2.41 \\
Religion & 2.83 \\
Social workers & 4.10 \\
Psychologist & 3.86 \\
Others & 4.87 \\
\hline
\end{tabular}




\section{APPENDIX - Questionnaire}

1) Do you think that male teenagers have a higher suicidal attempt rate than female teenagers?
a. Yes
b. No
c. I don't know

2) In the table below, there are several reasons for teenage suicidal attempts. Please rank the reasons according to the frequency in which you think they occur ( 1 being the most frequent and 13 being the least frequent).

\begin{tabular}{|l|l|l|}
\hline Reasons & Male & Female \\
\hline 2a. Financial problems & & \\
\hline 2b. Depression and/or hopelessness and/or loneliness & & \\
\hline 2c. Poor parent-child relationship & & \\
\hline 2d. Romantic relationship problems & & \\
\hline 2e. Peer rejection & & \\
\hline 2f. Stress & & \\
\hline 2g. History of mental disorder (e.g. panic attack, eating disorders, schizophrenia, & & \\
etc.) & & \\
\hline 2h. Atheism (not believing in the existence of God) & & \\
\hline 2i. Exposure to other people who have committed suicide & & \\
\hline 2j. Secularism (not religious or spiritual) & & \\
\hline 2k. Low self-esteem & & \\
\hline 2l. Past/present experiences of sexual abuse & & \\
\hline 2m. Others, please specify & & \\
\hline
\end{tabular}

3) In your opinion, where do you think teenagers obtain ideas to attempt suicide?
a. Television
b. Internet websites
c. Novel/story books/ real life stories
d. Peers/family

e. Others, please specify

4) In your opinion, which age group is more likely to attempt/commit suicide?
a. $13-15$
b. $16-18$
c. $19-20$ 
5) In the table below there are several methods that teenagers use for suicidal attempts. Please rank the methods according to the frequency in which you think they occur ( 1 being the most frequent and 9 being the least frequent).

\begin{tabular}{|l|l|l|}
\hline Methods & Male & Female \\
\hline 5a. Drug overdose (e.g. Ecstasy, Heroin, etc.) & & \\
\hline 5b. Sleeping pills & & \\
\hline 5c. Slit their wrist & & \\
\hline 5d. Jumping from heights & & \\
\hline 5e. Hanging & & \\
\hline 5f. Jumping in front of vehicles & & \\
\hline 5g. Burning themselves & & \\
\hline 5h. Drowning & & \\
\hline 5i. Others, please specify & & \\
\hline
\end{tabular}

6) In your opinion, whom do you think is responsible for teenage suicidal attempts?

a. Teenagers themselves

b. Parents

c. Society

d. Peers

7) In your opinion, which factors represent the best way to prevent teenage suicidal attempts? (Please rank: 1 being the most important and 6 being the least important).

\begin{tabular}{|l|l|}
\hline Factor & Importance \\
\hline 7a. Religion & \\
\hline 7b. Education & \\
\hline 7c. Social workers & \\
\hline 7d. Healthy relationship with parents & \\
\hline 7e. Psychologists & \\
\hline 7f. Others, please specify & \\
\hline
\end{tabular}

